Article

\title{
The Value of Oxygenation Saturation Index in Predicting the Outcomes of Patients with Acute Respiratory Distress Syndrome
}

\author{
Wan-Ling Chen ${ }^{1,+}$, Wei-Ting Lin ${ }^{2,+}$, Shu-Chen Kung ${ }^{1}$, Chih-Cheng Lai ${ }^{3}$ and \\ Chien-Ming Chao ${ }^{3, *}$ \\ 1 Department of Respiratory Therapy, Chi Mei Medical Center, Liouying, Tainan 73657, Taiwan; \\ wanlin0810@gmail.com (W.-L.C.); clh7810@mail.chimei.org.tw (S.-C.K.) \\ 2 Departments of Orthopedics and Trauma, Chi Mei Medical Center, Tainan 71004, Taiwan; \\ aapriliaa@gmail.com \\ 3 Department of Intensive Care Medicine, Chi Mei Medical Center, Liouying, Tainan 73657, Taiwan; \\ dtmed141@gmail.com \\ * Correspondence: ccm870958@yahoo.com.tw; Tel.: +886-06-622-6999 \\ + The authors contributed equally to this study.
}

Received: 25 July 2018; Accepted: 7 August 2018; Published: 8 August 2018

\begin{abstract}
This study aims to investigate the association between oxygenation saturation index (OSI) and the outcome of acute respiratory distress syndrome (ARDS) patients, and assess the predictive performance of OSI for ARDS patients' mortality. This study was conducted at one regional hospital with 66 adult intensive care unit (ICU) beds. All patients with ARDS were identified between November 12016 and May 31 2018, and their clinical information was retrospectively collected. The lowest $\mathrm{PaO}_{2} / \mathrm{FiO}_{2}$ ratio and $\mathrm{SpO}_{2} / \mathrm{FiO}_{2}$ ratio and highest mean airway pressure (MAP) were recorded on the first day of ARDS; and oxygen index (OI) and OSI were calculated as $\left(\mathrm{FiO}_{2} \times \mathrm{MAP}\right.$ $\times 100) / \mathrm{PaO}_{2}$, and $\left(\mathrm{FiO}_{2} \times \mathrm{MAP} \times 100\right) / \mathrm{SpO}_{2}$ accordingly. During the study period, a total of 101 patients with ARDS were enrolled, and their mean age was 69.2 years. The overall in-ICU and in-hospital mortality rate was $57.4 \%$ and $61.4 \%$, respectively. The patients with in-ICU mortality had higher APACHE II score than the survivors $(31.6 \pm 9.8$ vs. $23.0 \pm 9.1, p<0.001)$. In addition, mortalities had lower $\mathrm{SpO}_{2}$, and $\mathrm{SpO}_{2} / \mathrm{FiO}_{2}$ ratios than the survivors (both $p<0.05$ ). In contrast, survivors had lower OI, and OSI than the mortalities (both $p=0.008$ ). Both OSI (area under curve $(\mathrm{AUC})=0.656, p=0.008)$ and OI $(\mathrm{AUC}=0.654, p=0.008)$ had good predictive performance of mortality among ARDS patients using receiver-operating characteristics (ROC) curves analysis. In addition, the $\mathrm{AUC}$ of $\mathrm{SpO}_{2} / \mathrm{FiO}_{2}(\mathrm{AUC}=0.616, p=0.046)$ had better performance for mortality prediction than $\mathrm{PaO}_{2} / \mathrm{FiO}_{2}(\mathrm{AUC}=0.603, p=0.08)$. The patients with OSI greater than 12 had a higher risk of mortality than OSI < 12 (adjusted OR, 5.22, 95\% CI, 1.31-20.76, $p=0.019$ ). In contrast, $\mathrm{OI}, \mathrm{PaO}_{2} / \mathrm{FiO}_{2}$, and $\mathrm{SpO}_{2} / \mathrm{FiO}_{2}$ were not found to be significantly associated with increased mortality. OSI is significantly associated with the increased mortality of ARDS patients and can also be a good outcome predictor.
\end{abstract}

Keywords: $\mathrm{SpO}_{2} / \mathrm{FiO}_{2}$; acute respiratory distress syndrome; mortality; $\mathrm{PaO}_{2} / \mathrm{FiO}_{2}$

\section{Introduction}

Acute respiratory distress syndrome (ARDS) is an acute catastrophic lung condition that can be associated with high mortality [1-3]. In 1994, the American and European Consensus Conference (AECC) established specific clinical criteria for ARDS and acute lung injury (ALI), including acute and sudden onset of severe respiratory distress, bilateral infiltrates on chest radiography, the absence of 
cardiogenic pulmonary edema, and severe hypoxemia [4]. Until 2012, the Berlin definition of ARDS was proposed as three categories of ARDS based on the degree of hypoxemia: mild (200 $\mathrm{mm} \mathrm{Hg}<$ $\left.\mathrm{PaO}_{2} / \mathrm{FiO}_{2} \leq 300 \mathrm{~mm} \mathrm{Hg}\right)$, moderate $\left(100 \mathrm{~mm} \mathrm{Hg}<\mathrm{PaO}_{2} / \mathrm{FiO}_{2} \leq 200 \mathrm{~mm} \mathrm{Hg}\right)$ and severe $\left(\mathrm{PaO}_{2} / \mathrm{FiO}_{2}\right.$ $\leq 100 \mathrm{~mm} \mathrm{Hg}$ ) with a PEEP $\geq 5 \mathrm{~cm} \mathrm{H}_{2} \mathrm{O}$ [5]. No matter which criterion is applied for ARDS, severe hypoxemia remains the hallmark of ARDS. Therefore, various parameters of oxygenation are assessed as appropriate indicators of disease severity or good predictors of outcomes in several studies [6-9]. However, accurate analysis of oxygenation relies on the arterial blood gas measurement, and this test requires repeated arterial blood gas sampling. Thus, the concerns about the complications of arterial blood gas tests, including excess blood draws, increasing medical cost, and the implementation of arterial lines are raised. If we want to obtain accurate oxygenation measurement and avoid the arterial blood gas-associated complications, pulse oximetric measurement of oxygenation saturation $\left(\mathrm{SpO}_{2}\right)$ may provide a solution.

Through the help of noninvasive pulse oximetry, clinicians can obtain $\mathrm{SpO}_{2}$ and calculate the $\mathrm{SpO}_{2} / \mathrm{FiO}_{2}$ ratio, which has been demonstrated to be well correlated with the $\mathrm{PaO}_{2} / \mathrm{FiO}_{2}$ ratio among patients with mechanical ventilation and ARDS after using a nonlinear imputation strategy $[10,11]$. Moreover, DesPrez et al. showed that oxygenation saturation index (OSI) combining the $\mathrm{SpO}_{2} / \mathrm{FiO}_{2}$ ratio and mean airway pressure was well correlated with the oxygenation index (OI) and could be a reliable predictor of ARDS patients' outcome [12]. However, the accuracy of $\mathrm{SpO}_{2}$ measurement may be affected by several factors, such as hypoperfusion, abnormal hemoglobin, severe anemia, or use of vasopressor, and we wonder whether OSI based on the measurement of $\mathrm{SpO}_{2}$ can perform well in all of the various clinical conditions in ARDS. Therefore, we conduct this retrospective study to investigate the association between OSI and the outcome of ARDS patients, and assess the predictive performance of OSI for ARDS patients' mortality.

\section{Patients and Methods}

\subsection{Patients and Hospital Setting}

This study was conducted at one regional hospital with 66 adult adult intensive care unit (ICU) beds. The care in the ICU is conducted by ICU teams, including intensivists, senior residents, nurses, respiratory therapists, dietitians, physical therapists, and clinical pharmacists. The ICU team makes rounds at least once daily, and respiratory therapists are responsible for managing all mechanical ventilation $(\mathrm{MV})$, including weaning processes and spontaneous breathing trials. Patients who were admitted to ICUs and met the American-European Consensus Conference (AECC) definition of ARDS were identified between 1 November 2016 and 31 May 2018. Ethics approval was obtained from the Institution Review Board of Chi Mei Medical Center.

\subsection{Variables Measurements}

The following information of the included patients, including age; gender; co-morbidities; cause of ARDS; clinical features; laboratory data; comorbidities including congestive heart failure, chronic lung diseases, chronic kidney disease, liver cirrhosis, diabetes mellitus, cancer, and immunocompromised condition; and Acute Physiology and Chronic Health Evaluation (APACHEII) score were collected. The primary outcome was all-cause in-ICU mortality, and secondary outcomes included in-hospital mortality, length of ICU and hospital stays, and MV duration. In addition, the results of arterial blood gas (ABG); $\mathrm{SpO}_{2}$ and ventilator setting including $\mathrm{FiO}_{2}$, tidal volume, positive end-expiratory pressure (PEEP), and mean airway pressure (MAP) were obtained. In addition, the lowest $\mathrm{PaO}_{2} / \mathrm{FiO}_{2}$ ratio and $\mathrm{SpO}_{2} / \mathrm{FiO}_{2}$ ratio were recorded on the first day of ARDS. $\mathrm{SpO}_{2}$ was used to calculate oxygenation saturation index and $\mathrm{SpO}_{2} / \mathrm{FiO}_{2}$ ratio if the $\mathrm{SpO}_{2}<97 \%$ as previous study [12]. 


\subsection{Definitions}

The shock was defined as systolic blood pressure (SBP) of $\leq 90 \mathrm{mmHg}$ or a mean arterial pressure (MAP) $\leq 65 \mathrm{mmHg}$ for at least 1 hour despite adequate fluid resuscitation; or the need for vasoactive agents to maintain SBP $\geq 90 \mathrm{mmHg}$ or mean arterial pressure $\geq 65 \mathrm{mmHg}$. ARDS was diagnosed according to AECC criteria-severe hypoxemia including $\mathrm{PaO}_{2} / \mathrm{FiO}_{2}$ ratio less than $200 \mathrm{mmHg}$, bilateral infiltrates on chest $\mathrm{X}$-ray, and no evidence of cardiogenic pulmonary edema [4]. Oxygen index (OI) was defined as $\left(\mathrm{FiO}_{2} \times \mathrm{MAP} \times 100\right)$ divided by $\mathrm{PaO}_{2}$, and Oxygenation saturation index (OSI) was defined as $\left(\mathrm{FiO}_{2} \times \mathrm{MAP} \times 100\right)$ divided by $\mathrm{SpO}_{2}$.

\subsection{Statistical Analysis}

Continuous variables were reported as the mean and standard deviation (SD). Categorical variables were presented as frequency counts with percentages. In addition, the differences of baseline characteristics and clinical variables between the survival and non-survival groups were evaluated using Student's test (for continuous variables) and Pearson's chi-squared test (for categorical variables). Receiver-operating characteristics (ROC) curves were used to assess the predictive value of different severity indexes for the outcome of ARDS patients and to determine the best cut off values of OSI and OI for the outcome prediction. All statistical analyses were conducted using the statistical package SPSS for Windows (Version 19.0, SPSS, Chicago, IL, USA), and a $p$ value $<0.05$ was considered to show statistical significance.

\section{Results}

During the study period, a total of 101 patients with ARDS were enrolled, and their mean age was 69.2 years. The mean APACHE II scores were $27.9 \pm 10.4$. Only eight patients had extra-pulmonary ARDS. Pneumonia was the most common cause of ARDS $(n=94,94.1 \%)$, followed by sepsis $(n=5$, $5.0 \%$ ). In addition, each patient had major trauma and acute pancreatitis-related ARDS. Among them, $81(80.2 \%)$ patients had an initial presentation of shock. Malignancy was the most common underlying diseases $(n=42,41.6 \%)$, followed by diabetes mellitus $(n=33,32.7 \%)$, chronic kidney disease $(n=21$, $20.8 \%)$, liver cirrhosis $(n=11,10.9 \%)$, congestive heart failure $(n=8,7.9 \%)$, and chronic lung disease $(n$ $=5,5.0 \%$ ). The median hemoglobin and total-bilirubin was $9.9 \mathrm{~g} / \mathrm{dL}(8.8-11.4)$ and $1.0 \mathrm{mg} / \mathrm{dL}(0.5-2.0)$, respectively. The median MV duration was 12.0 days (5-21.8). The overall in-ICU and in-hospital mortality rate was $57.4 \%$ and $61.4 \%$, respectively. The median length of stay in ICU and hospital was 13.0 days (4.3-25.8) and 18.0 days (4.3-33.3), respectively.

The patients had in-ICU mortality had higher APACHE II score than the survivors (31.6 $\pm 9.8 \mathrm{vs}$. $23.0 \pm 9.1, p<0.001$ ). In addition, the patients with mortality had lower $\mathrm{SpO}_{2}$ and $\mathrm{SpO}_{2} / \mathrm{FiO}_{2}$ ratios than the survivors (both $p<0.05$ ). In contrast, survivors had lower OI, and OSI than the mortalities (both $p=0.008$ ). However, there were no significant differences in terms of age, gender, the cause of ARDS, the presence of shock, underlying disease and the findings of laboratory examinations between non-survivors and survivors (Table 1 ). 
Table 1. Clinical characteristics of patients with ARDS.

\begin{tabular}{|c|c|c|c|c|}
\hline Variables & $\begin{array}{l}\text { No }(\%) \text { of Patients } \\
(n=101)\end{array}$ & $\begin{array}{l}\text { No }(\%) \text { of Survivors } \\
(n=43)\end{array}$ & $\begin{array}{l}\text { No }(\%) \text { of Mortalities } \\
(n=58)\end{array}$ & $p$ Value * \\
\hline Age (years) & $69.2 \pm 13.5$ & $66.7 \pm 14.4$ & $71.0 \pm 12.7$ & 0.12 \\
\hline \multicolumn{5}{|l|}{ Gender } \\
\hline Male & $63(62.4)$ & $25(58.1)$ & $38(65.5)$ & \multirow{2}{*}{0.45} \\
\hline Female & 38 (37.6) & 18 (41.9) & $20(34.5)$ & \\
\hline APACHE II scores & $27.9 \pm 10.4$ & $23.0 \pm 9.1$ & $31.6 \pm 9.8$ & $<0.001$ \\
\hline Extra-pulmonary ARDS & $8(7.9)$ & $3(7.0)$ & $5(8.6)$ & 0.76 \\
\hline \multicolumn{5}{|l|}{ Cause of ARDS } \\
\hline Pneumonia & $94(94.1)$ & $40(93.0)$ & $54(93.1)$ & \multirow{4}{*}{0.29} \\
\hline Sepsis & $5(5.0)$ & $1(2.3)$ & $4(6.9)$ & \\
\hline Major trauma & $1(1.0)$ & $1(2.3)$ & $0(0)$ & \\
\hline Acute pancreatitis & $1(1.0)$ & $1(2.3)$ & $0(0)$ & \\
\hline Shock & $81(80.2)$ & $32(74.4)$ & 49 (84.5) & 0.21 \\
\hline \multicolumn{5}{|l|}{ Underlying disease } \\
\hline Chronic lung disease & $5(5.0)$ & $1(2.3)$ & $4(6.9)$ & 0.30 \\
\hline Chronic kidney disease & $21(20.8)$ & $10(23.3)$ & $11(19.0)$ & 0.60 \\
\hline Congestive heart failure & $8(7.9)$ & $2(4.7)$ & $6(10.3)$ & 0.30 \\
\hline Liver cirrhosis & $11(10.9)$ & $5(11.6)$ & $6(10.3)$ & 0.84 \\
\hline Diabetes mellitus & $33(32.7)$ & $15(34.9)$ & $18(31.0)$ & 0.68 \\
\hline Malignancy & 42 (41.6) & $15(34.9)$ & $27(46.6)$ & 0.24 \\
\hline \multicolumn{5}{|l|}{ Ventilator setting } \\
\hline PEEP & $10(10-12)$ & $10(10-12)$ & $10(10-12)$ & 0.47 \\
\hline $\mathrm{Vt}$ & $450(410-549)$ & $476(420-557)$ & $450(400-534)$ & 0.13 \\
\hline \multicolumn{5}{|l|}{ Laboratory findings } \\
\hline Hemoglobin & $9.9(8.8-11.4)$ & $9.9(9.7-17.2)$ & $9.9(9.2-10.9)$ & 0.96 \\
\hline Total-bilirubin & $1.0(0.5-2.0)$ & $0.8(0.5-1.6)$ & $1.1(0.6-2.4)$ & 0.16 \\
\hline $\mathrm{pH}$ & $7.35(7.28-7.41)$ & $7.35(7.28-7.41)$ & $7.34(7.28-7.42)$ & 0.98 \\
\hline $\mathrm{HCO}_{3}{ }^{-}$ & $20.3(16.9-24.1)$ & $20.3(17.0-22.5)$ & $20.0(16.4-26.1)$ & 0.91 \\
\hline Lowest $\mathrm{PaO}_{2}$ & $72.0(64.2-83.1)$ & $72.2(64.3-83.2)$ & $71.7(63.4-83.4)$ & 0.71 \\
\hline Lowest $\mathrm{SpO}_{2}$ & $90.0(85.5-92.5)$ & $92.0(90.0-94.0)$ & $88.0(80.8-91.3)$ & $<0.001$ \\
\hline Lowest $\mathrm{PaO}_{2} / \mathrm{FiO}_{2}$ ratio & $108.8(91.7-138.3)$ & $114.0(100.9-145.6)$ & $106.0(88.7-130.0)$ & 0.08 \\
\hline Lowest $\mathrm{SpO}_{2} / \mathrm{FiO}_{2}$ ratio & $145.0(116.3-186.0)$ & $148.3(130.7-190.0)$ & $139.3(102.1-163.5)$ & 0.046 \\
\hline Highest mean airway pressure & $21.0(19.5-23.0)$ & $21.0(18.0-22.0)$ & $21.5(20.0-24.0)$ & 0.012 \\
\hline Oxygenation index & $19.0(15.0-23.5)$ & $15.9(13.7-22.1)$ & $20.5(16.0-26.6)$ & 0.008 \\
\hline Oxygenation saturation index & $15.0(11.3-18.2)$ & $13.6(9.7-17.2)$ & $16.0(12.9-21.4)$ & 0.008 \\
\hline \multicolumn{5}{|l|}{ Outcome } \\
\hline MV duration & $12.0(5-21.8)$ & $15.5(8.8-32.5)$ & $8.0(3.4-19.0)$ & 0.002 \\
\hline ICU LOS & $13.0(4.3-25.8)$ & $19.0(10.8-38)$ & $7.0(2.8-18.0)$ & $<0.001$ \\
\hline Hospital LOS & $18.0(4.3-33.3)$ & $32.5(19.5-48.5)$ & $7.0(2.8-18.0)$ & $<0.001$ \\
\hline
\end{tabular}

* Comparison between survivors and mortalities.

Using the ROC curve, we assessed the individual performance of OI, OSI, $\mathrm{PaO}_{2} / \mathrm{FiO}_{2}$, and $\mathrm{SpO}_{2} / \mathrm{FiO}_{2}$ to predict in-ICU mortality (Table 2). Both OSI (AUC $=0.656, p=0.008$ ) and OI (AUC $=0.654, p=0.008$ ) had good predictive performance of mortality among ARDS patients (Figure 1 ), and the best cutoff value for OSI and OI was 12 and 16, respectively. In addition, the $\mathrm{AUC}$ of $\mathrm{SpO}_{2} / \mathrm{FiO}_{2}$ (AUC $=0.616, p=0.046)$ had better performance for mortality prediction than $\mathrm{PaO}_{2} / \mathrm{FiO}_{2}(\mathrm{AUC}=0.603$, $p=0.08$ ) (Figure 2). The best cutoff value for $\mathrm{SpO}_{2} / \mathrm{FiO}_{2}$ ratio was 142 . Furthermore, we analyzed the association between mortality of ARDS patients and these four indices-OI, OSI, $\mathrm{PaO}_{2} / \mathrm{FiO}_{2}$, and $\mathrm{SpO}_{2} / \mathrm{FiO}_{2}$ (Table 3). We found only OSI were significantly associated with increased mortality. The patients with OSI greater than 12 had the higher risk of mortality than OSI < 12 (adjusted OR, 5.22, 95\% CI, 1.31-20.76, $p=0.019$ ). In contrast, $\mathrm{OI}, \mathrm{PaO}_{2} / \mathrm{FiO}_{2}$, and $\mathrm{SpO}_{2} / \mathrm{FiO}_{2}$ were not found to be significantly associated with increased mortality. 
Table 2. Comparison of areas under the receiver-operating characteristic (ROC) curve for discrimination of mortality of ARDS for four indices of oxygenation.

\begin{tabular}{cccc}
\hline Measure & Area under the ROC Curve & $\mathbf{9 5 \%}$ CI & $p$ Value \\
\hline Lowest $\mathrm{PaO}_{2} / \mathrm{FiO}_{2}$ ratio & 0.603 & $0.492-0.714$ & 0.08 \\
Lowest $\mathrm{SpO}_{2} / \mathrm{FiO}_{2}$ ratio & 0.616 & $0.506-0.726$ & 0.046 \\
Oxygenation index & 0.654 & $0.547-0.761$ & 0.008 \\
Oxygen saturation index & 0.656 & $0.548-0.763$ & 0.008 \\
\hline
\end{tabular}

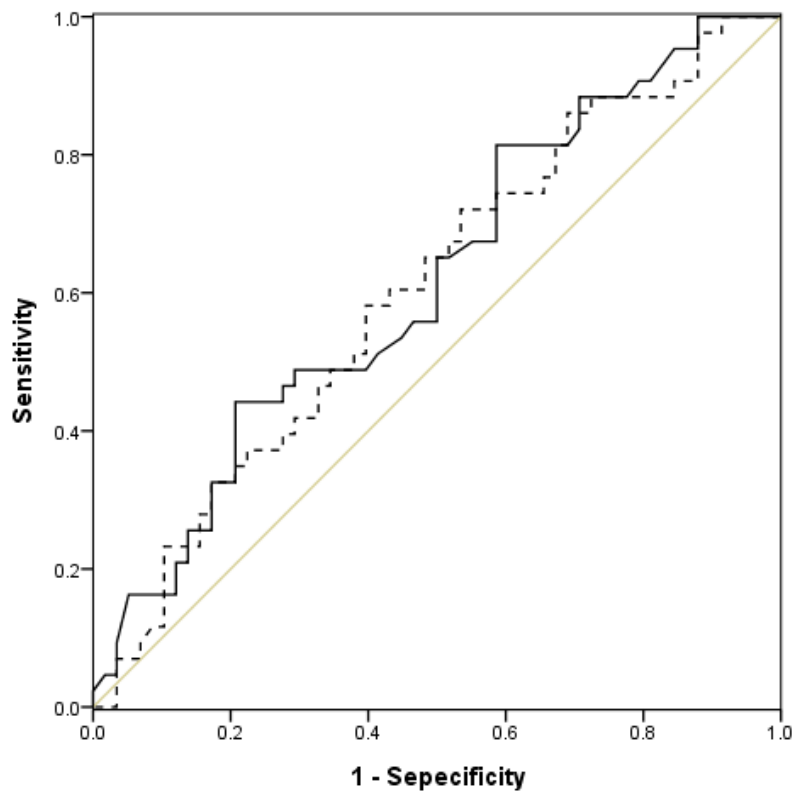

Figure 1. Receiver-operative characteristics (ROC) curves of oxygenation saturation index (continuous line) and oxygenation index (dotted line) for mortality prediction.

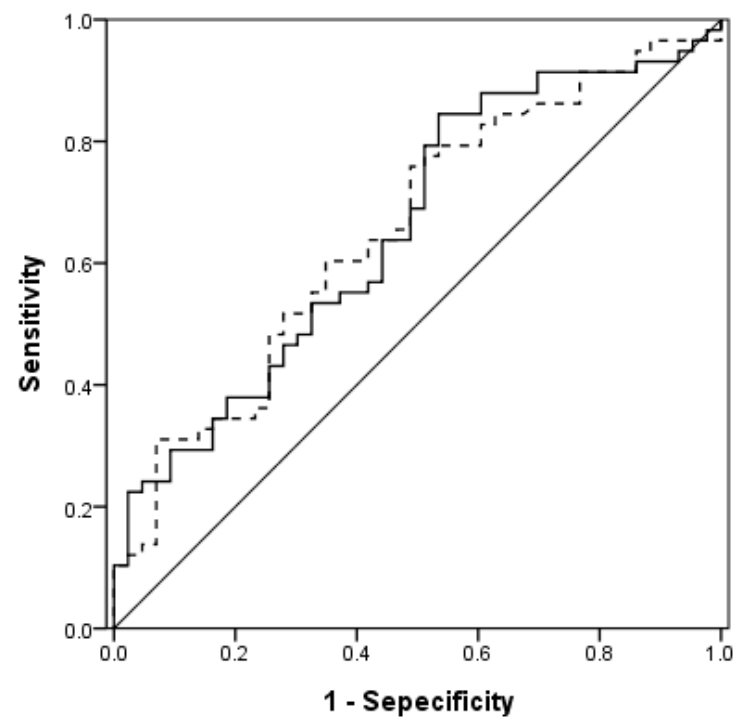

Figure 2. Receiver-operative characteristics (ROC) curves of $\mathrm{SpO}_{2} / \mathrm{FiO}_{2}$ (continuous line) and $\mathrm{PaO}_{2} / \mathrm{FiO}_{2}$ (dotted line) for mortality prediction. 
Table 3. Risk factor of in-ICU mortality.

\begin{tabular}{llll}
\hline Variable & OR & $\mathbf{9 5 \%}$ CI & $p$ Value \\
\hline $\begin{array}{l}\text { Lowest } \mathrm{PaO}_{2} / \mathrm{FiO}_{2} \text { ratio } \\
\quad \leq 100\end{array}$ & 1 & & \\
$\quad>100$ & 0.794 & $0.25-2.52$ & 0.7 \\
\hline $\begin{array}{l}\text { Lowest } \mathrm{SpO}_{2} / \mathrm{FiO}_{2} \text { ratio } \\
\quad \leq 142\end{array}$ & 1 & & \\
$\quad>142$ & 0.36 & $0.09-1.35$ & 0.13 \\
\hline $\begin{array}{l}\text { Oxygenation index } \\
\quad<16\end{array}$ & 1 & & \\
$\quad \geq 16$ & 2.92 & $0.98-8.68$ & 0.054 \\
\hline $\begin{array}{l}\text { Oxygenation saturation index } \\
\quad<12\end{array}$ & 1 & & \\
$\quad \geq 12$ & 5.22 & $1.31-20.76$ & 0.019 \\
\hline
\end{tabular}

OR, odds ratio; $\mathrm{CI}=$ confidence interval.

\section{Discussion}

In this study, we found that OSI was significantly associated with increased mortality of ARDS patients. Moreover, it had a similar performance for mortality prediction to OI, but better than the other two oxygenation parameters- $\mathrm{PaO}_{2} / \mathrm{FiO}_{2}$, and $\mathrm{SpO}_{2} / \mathrm{FiO}_{2}$. Based on this finding, it suggests that OSI as a noninvasive parameter can provide useful information of ARDS outcome. This is consistent with DesPrez et al.'s findings [12] that OSI was independently associated with hospital mortality (OR, 1.228; 95\% CI, 1.056-1.429), and the AUC for mortality prediction was greater for OSI (AUC, 0.602; $p=0.007$ ) than the other three oxygenation parameter-OI, $\mathrm{PaO}_{2} / \mathrm{FiO}_{2}$, and $\mathrm{SpO}_{2} / \mathrm{FiO}_{2}$. In contrast, the clinical characteristics of ARDS patients in the present study were significantly different from DesPrez et al.'s study. Most of the patients were elderly, aged $\geq 65$ years in our study. In addition, $82(81.2 \%)$ patients had a hemoglobin $<12 \mathrm{~g} / \mathrm{dL}$, and $81(80.2 \%)$ patients had shock in this study. Although the accuracy of pulse oximeter may be influenced by some clinical conditions, such as hypoperfusion and anemia, our findings indicated that OSI could preserve fair performance in the outcome prediction of ARDS patients in the patients with shock or elderly patients. Finally, we found that the OSI cutoff value of 12 had the best predictive performance and the patients with OSI $\geq 12$ had five times the risk of death than the patients with OSI $<12$. Overall, it should suggest that OSI could be a good prognostic indicator of ARDS patients.

Besides the comparison between OSI and OI, we recorded $\mathrm{PaO}_{2} / \mathrm{FiO}_{2}$, and $\mathrm{SpO}_{2} / \mathrm{FiO}_{2}$ for comparison. According to ROC curve analysis, we found that the predictive performance of $\mathrm{PaO}_{2} / \mathrm{FiO}_{2}$, and $\mathrm{SpO}_{2} / \mathrm{FiO}_{2}$ were similar. This is consistent with Brown et al.'s study [10] that mortalities of ARDS patients were similar on the bases of measured $\mathrm{PaO}_{2} / \mathrm{FiO}_{2}$ and $\mathrm{SpO}_{2} / \mathrm{FiO}_{2}$. Even for diagnosing ARDS, Chen et al. [13] showed that the clinical characteristics and outcome of ARDS patients diagnosed by $\mathrm{SpO}_{2} / \mathrm{FiO}_{2}$ were similar compared with diagnosed by $\mathrm{PaO}_{2} / \mathrm{FiO}_{2}$. In summary, $\mathrm{SpO}_{2}$, which is non-invasively measured by the pulse oximeter and can provide the continuous monitor of oxygenation, can be considered as a good surrogate of ARDS mortality compared to $\mathrm{PaO}_{2}$ which requires sampling of arterial blood for analysis.

No matter in the Berlin definition [5] or AECC criteria [4], $\mathrm{PaO}_{2} / \mathrm{FiO}_{2}$ was an important indicator for diagnosing ARDS and was commonly used to represent the severity of ARDS. Although the Berlin criteria showed the better predictive power of mortality in ARDS than the AECC definition, the absolute value of AUC on the ROC analysis was only 0.577 [14]. Another prospective observation study also found that ARDS severity was not significantly associated with the mortality in the Cox proportional hazard regression analysis $(p=0.84)$ [15]. In fact, more and more studies [9] showed that $\mathrm{PaO}_{2} / \mathrm{FiO}_{2}$ may not be a good prognostic factor of ARDS. In this study, $\mathrm{PaO}_{2} / \mathrm{FiO}_{2}$ was not found 
to be significantly associated with the mortality of ARDS patients and showed the poor predictive performance of OI using ROC analyses.

This study had several limitations. First, this study was conducted in a single medical center, and the patient number was limited. Therefore, our findings may not be generalized to other hospitals. Second, ARDS can be caused by many diseases; however, more than 90\% of ARDS cases in this study were caused by pneumonia. Third, we do not have the cases of carbon monoxide poisoning, methemoglobin intoxication or hyperbilirubinemia, which may affect the measurement of the pulse oximeter. Overall, a further large and multicenter study is warranted to confirm our findings.

In conclusion, OSI is significantly associated with the increased mortality of ARDS patients and can also be a good outcome predictor.

Author Contributions: Conceptualization, W.-L.C. and C.-C.L.; Methodology, W.-L.C. and W.-T.L.; Formal Analysis, W.-L.C. and S.-C.K.; Investigation, W.-T.L., C.-C.L., and C.-M.C.; Resources, S.-C.K.; Writing-Original Draft Preparation, C.-C.L.; Writing-Review \& Editing, C.-M.C.; Supervision, C.-M.C.

Conflicts of Interest: The authors declare no conflict of interest.

\section{References}

1. Phua, J.; Badia, J.R.; Adhikari, N.K.; Friedrich, J.O.; Fowler, R.A.; Singh, J.M.; Scales, D.C.; Stather, D.R.; Li, A.; Jones, A.; et al. Has mortality from acute respiratory distress syndrome decreased over time? A systematic review. Am. J. Respir. Crit. Care Med. 2009, 179, 220-227. [CrossRef] [PubMed]

2. Villar, J.; Blanco, J.; Añón, J.M.; Santos-Bouza, A.; Blanch, L.; Ambrós, A.; Gandía, F.; Carriedo, D.; Mosteiro, F.; Basaldúa, S.; et al. The ALIEN study: Incidence and outcome of acute respiratory distress syndrome in the era of lung protective ventilation. Intensive Care Med. 2011, 37, 1932-1941. [CrossRef] [PubMed]

3. Villar, J.; Sulemanji, D.; Kacmarek, R.M. The acute respiratory distress syndrome: Incidence and mortality, has it changed? Curr. Opin. Crit. Care 2014, 20,3-9. [CrossRef] [PubMed]

4. Bernard, G.R.; Artigas, A.; Brigham, K.L.; Carlet, J.; Falke, K.; Hudson, L.; Lamy, M.; Legall, J.R.; Morris, A.; Spragg, R. The American-European consensus conference on ARDS. Definitions, mechanisms, relevant outcomes, and clinical trial coordination. Am. J. Respir. Crit. Care Med. 1994, 149, 818-824. [CrossRef] [PubMed]

5. Ranieri, V.M.; Rubenfeld, G.D.; Thompson, B.T.; Ferguson, N.D.; Caldwell, E.; Fan, E.; Camporota, L.; Slutsky, A.S.; Antonelli, M.; Anzueto, A.; et al. Acute respiratory distress syndrome: The Berlin Definition. JAMA 2012, 307, 2526-2533. [PubMed]

6. Cooke, C.R.; Kahn, J.M.; Caldwell, E.; Okamoto, V.N.; Heckbert, S.R.; Hudson, L.D.; Rubenfeld, G.D. Predictors of hospital mortality in a population-based cohort of patients with acute lung injury. Crit. Care Med. 2008, 36, 1412-1420. [CrossRef] [PubMed]

7. Villar, J.; Pérez-Méndez, L.; Basaldúa, S.; Blanco, J.; Aguilar, G.; Toral, D.; Zavala, E.; Romera, M.A.; González-Díaz, G.; Nogal, F.D.; et al. A risk tertiles model for predicting mortality in patients with acute respiratory distress syndrome: Age, plateau pressure, and $\mathrm{P}(\mathrm{aO}(2)) / \mathrm{F}(\mathrm{IO}(2))$ at ARDS onset can predict mortality. Respir. Care 2011, 56, 420-428. [CrossRef] [PubMed]

8. Lai, C.C.; Sung, M.I.; Ho, C.H.; Liu, H.H.; Chen, C.M.; Chiang, S.R.; Chao, C.M.; Liu, W.L.; Hsing, S.C.; Cheng, K.C. The prognostic value of N-terminal proB-type natriuretic peptide in patients with acute respiratory distress syndrome. Sci. Rep. 2017, 7, 44784. [CrossRef] [PubMed]

9. Lai, C.C.; Sung, M.I.; Liu, H.H.; Chen, C.M.; Chiang, S.R.; Liu, W.L.; Chao, C.M.; Ho, C.H.; Weng, S.F.; Hsing, S.C.; et al. The ratio of partial pressure arterial oxygen and fraction of inspired oxygen 1 day after acute respiratory distress syndrome onset can predict the outcomes of involving patients. Medicine 2016, 95, e3333. [CrossRef] [PubMed]

10. Brown, S.M.; Duggal, A.; Hou, P.C.; Tidswell, M.; Khan, A.; Exline, M.; Park, P.K.; Schoenfeld, D.A.; Liu, M.; Grissom, C.K.; et al. Nonlinear imputation of $\mathrm{PaO}_{2} / \mathrm{FIO}_{2}$ from $\mathrm{SpO}_{2} / \mathrm{FIO}_{2}$ among mechanically ventilated patients in the ICU: A prospective, observational study. Crit. Care Med. 2017, 45, 1317-1324. [CrossRef] [PubMed] 
11. Brown, S.M.; Grissom, C.K.; Moss, M.; Rice, T.W.; Schoenfeld, D.; Hou, P.C.; Thompson, B.T.; Brower, R.G.; $\mathrm{NIH} /$ NHLBI PETAL Network Collaborators. Nonlinear imputation of $\mathrm{PaO}_{2} / \mathrm{FiO}_{2}$ from $\mathrm{SpO}_{2} / \mathrm{FiO}_{2}$ among patients with acute respiratory distress syndrome. Chest 2016, 150, 307-313. [CrossRef] [PubMed]

12. DesPrez, K.; McNeil, J.B.; Wang, C.; Bastarache, J.A.; Shaver, C.M.; Ware, L.B. Oxygenation saturation index predicts clinical outcomes in ARDS. Chest 2017, 152, 1151-1158. [CrossRef] [PubMed]

13. Chen, W.; Janz, D.R.; Shaver, C.M.; Bernard, G.R.; Bastarache, J.A.; Ware, L.B. Clinical characteristics and outcomes are similar in ARDS diagnosed by oxygen saturation $/ \mathrm{FiO}_{2}$ ratio compared with $\mathrm{PaO}_{2} / \mathrm{FiO}$ ratio. Chest 2015, 148, 1477-1483. [CrossRef] [PubMed]

14. Barbas, C.S.; Isola, A.M.; Caser, E.B. What is the future of acute respiratory distress syndrome after the Berlin definition? Curr. Opin. Crit. Care 2014, 20, 10-16. [CrossRef] [PubMed]

15. Hernu, R.; Wallet, F.; Thiollière, F.; Martin, O.; Richard, J.C.; Schmitt, Z.; Wallon, G.; Delannoy, B.; Rimmelé, T.; Démaret, $\mathrm{C}$; et al. An attempt to validate the modification of the American-European consensus definition of acute lung injury/acute respiratory distress syndrome by the Berlin definition in a university hospital. Intensive Care Med. 2013, 39, 2161-2170. [CrossRef] [PubMed]

(C) 2018 by the authors. Licensee MDPI, Basel, Switzerland. This article is an open access article distributed under the terms and conditions of the Creative Commons Attribution (CC BY) license (http:// creativecommons.org/licenses/by/4.0/). 